Historic, Archive Document

Do not assume content reflects current scientific knowledge, policies, or practices. 



\title{
Cop: 2 \\ Productivity Equations for \\ Forest Vegetation Treatment Projects in the Colorado Front Range
}

\author{
Mary Lou Richardson \\ David R. Betters \\ George R. Sampson
}

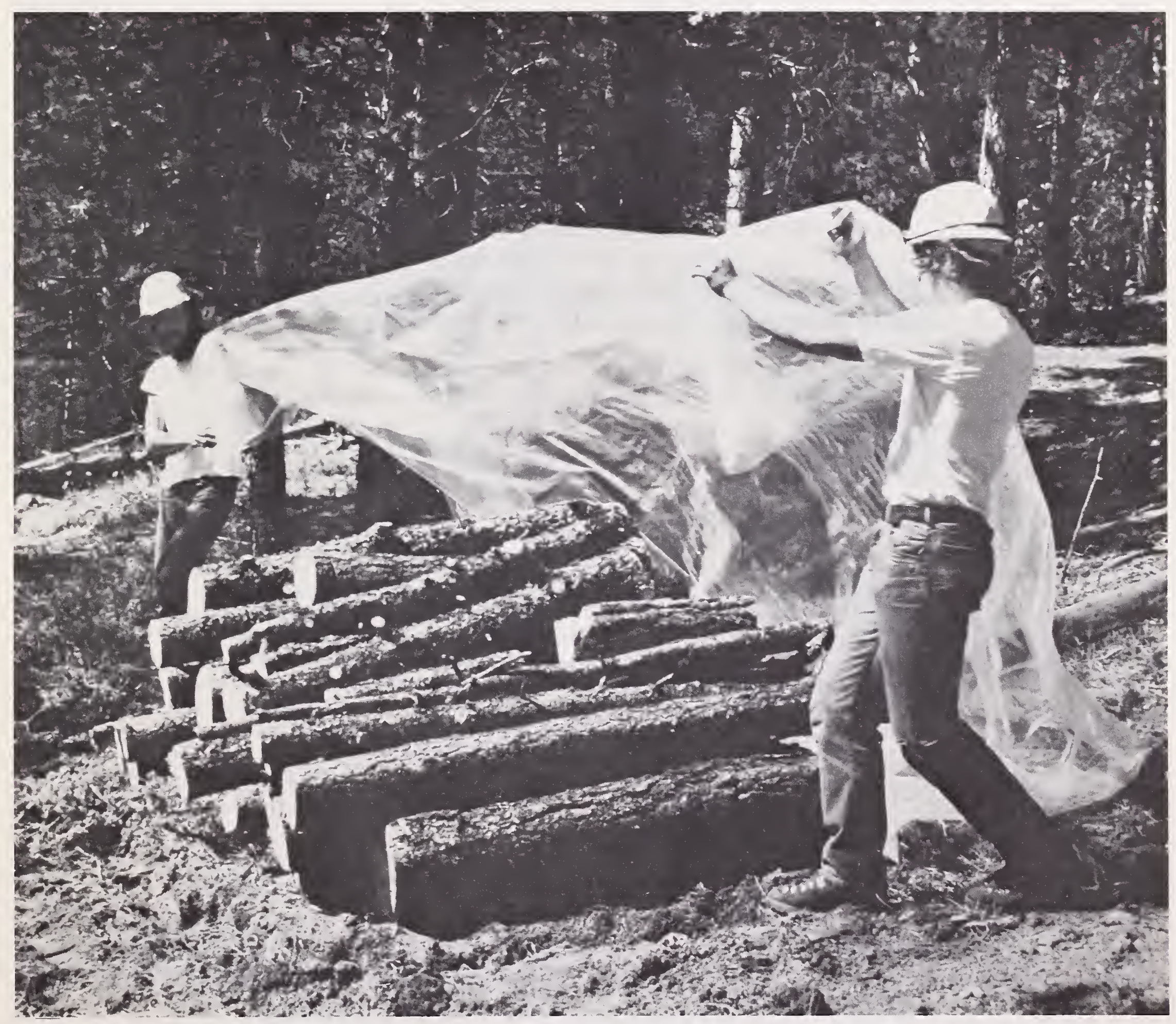




\title{
Productivity Equations for Forest Vegetation Treatment Projects in the Colorado Front Range
}

\author{
Mary Lou Richardson, Graduate Student \\ David R. Betters, Associate Professor \\ Colorado State University \\ George R. Sampson, Market Analyst \\ Rocky Mountain Forest and Range Experiment Station'
}

\begin{abstract}
Regression equations have been developed which relate labor and equipment hours required for various treatment methods to characteristics of the terrain, size of job, and worker efficiency. The equations can be used for other Front Range areas. This report also offers recommendations for improvement of vegetation management programs.
\end{abstract}




\title{
Productivity Equations for Forest Vegetation Treatment Projects in the Colorado Front Range
}

\author{
Mary Lou Richardson, David R. Betters, and George R. Sampson
}

\section{MANAGEMENT IMPLICATIONS}

The equations and analyses presented here were designed to provide cost prediction information and identify major cost determinants of beetle-control treatments. However, the study also provides a basis for analyzing cost determinants of other insect control programs.

The equations have several applications. They can be used by a forest manager or private landowner to (1) obtain cost estimates for a particular beetle control technique before it is begun, (2) determine the program which would produce the most treated acres given a limited budget, (3) estimate the level of work possible at a given cost for tracts under certain conditions, and (4) determine whether a bid from a private contractor is realistic.

Although the prediction equations suffer the limitation of being based on a small sample, the relationships represented are statistically significant and are useful in estimating cost and time requirements of certain treatments. They also can be used to predict total hours required. Although they provide only rough estimates, they offer a much more accurate forecast of costs than was available in planning and implementing the first year of the Front Range Vegetative Management Pilot Project. Forest managers and landowners will have to decide whether to use the year 1 equations (based on first-year Pilot Project data) or year 2 equations (based on second-year Pilot Project data). This choice should reflect their situations. Start-up periods of vegetation management programs are likely to be more costly. Equations developed from year 1 data are recommended for these periods. Equations for year 2 generally would be better predictors for subsequent periods. Also, if the forest manager or landowner feels the crew is rather inexperienced, or that work on a specific job may be interrupted frequently, it may be better to use year 1 equations. A certain amount of testing on the site might be desirable before selecting the equations for a particular situation.

\section{INTRODUCTION}

The Front Range Vegetative Management Pilot Project was implemented in 1978 in response to a catastrophic and worsening epidemic of the mountain pine beetle along Colorado's Front Range. The Pilot
Project's goals were fuels management, direct beetle control, timber stand improvement (TSI), and esthetic enhancement. More than 34,000 acres of public and private forest land in Boulder County (fig. 1) were chosen as the first target of this continuing management effort because of the especially severe infestation, increased forest fire danger as a result of trees killed by the insects, intense political pressure, and the fact that Boulder County includes a mix of forest land ownerships typical of the Front Range. It was hoped that successful elements of the beetle-control program could be extended to an additional 300,000 acres of Front Range forests in similar condition.

The Colorado State Forest Service (CSFS) conducted most of the field activities required by this project, coordinating its activities with the USDA Forest
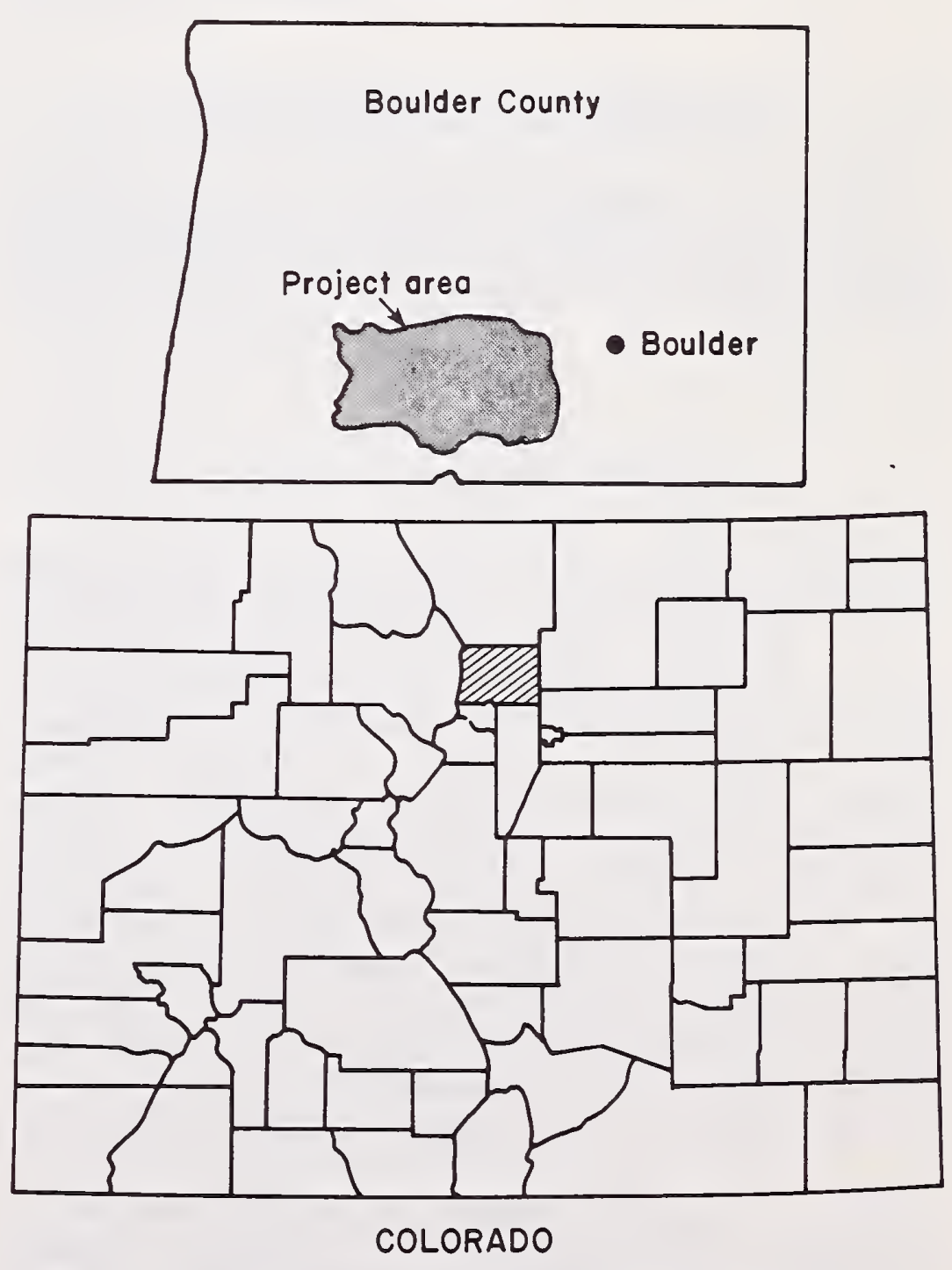

Figure 1.-Front Range Project location map. 
Service (USFS), Boulder County, the City of Boulder, the Bureau of Land Management (BLM), and private organizations.

The purpose of the research reported here was to help evaluate the productivity of various treatment activities carried out in the Pilot Project and to make general recommendations regarding efficiency improvement and other program aspects. ${ }^{2}$

Cost analysis is an important part of any forestry program, especially one that is intended to be a continuing effort. Because actual procedures applied in Boulder County may be implemented in other locations along the Front Range, key variables affecting costs and ways to minimize expenditures must be identified. This study provides productivity guidelines that should make it possible to deal more effectively with costs when similar treatments are applied elsewhere.

The urgent nature and timing of the Pilot Project did not allow much preplanning. As a result, lack of an adequate data collection system and available records was a problem. In addition to the need for more complete data, it is important to assess all elements of the treatment processes that affect costs and, if significant, to include them in prediction models. The more variability in costs that can be accounted for through improved data collection or by addition of new variables in the model, the more precise the model will be in predicting actual treatment costs.

\section{TREATMENT PRESCRIPTIONS}

Broad management prescriptions were developed for each forest condition. These prescriptions were refined and adapted for specific stands within the Pilot Project area.

\section{Timber Stand Improvement}

Specified timber stand improvement (TSI) prescriptions called for thinning of live trees to reduce stand density in mature and overmature stands and for removing infested and dead or dying trees. The removed material was either sold or made available to the public free of charge. Where there was a market for the timber, it was sold as stumpage. Where there was no market for stumpage, but marketable products could be made from the timber removed, the timber was cut by TSI crews and sold at roadside. Revenue from these sales was used to help defray treatment costs. Standard slash disposal methods were used where it was not economically feasible to remove this material. Prediction equations were developed for TSI activities, including thinning of green trees, removal of dead and in-

\footnotetext{
${ }^{2}$ For a more complete description of this study, see: Mary Lou Richardson, Costs and Returns for the Front Range Vegetative Management Pilot Project. Master of Forestry Thesis. Colorado State University, Spring, 1979.
}

fested trees, and slash disposal. Both state-employed and contract crews were engaged in TSI activities. However, only data for state crews were adequate for use in developing the prediction equations.

\section{Thinning}

The purpose of thinning in the Pilot Project was to reduce the susceptibility of stands to mountain pine beetle attack. Few facts were known about this relationship for the Front Range. But previous observations in the Black Hills indicated that mountain pine beetle outbreaks usually develop in portions of unmanaged ponderosa pine stands with basal areas greater than 150 square feet per acre, with most trees more than 8 inches d.b.h. (Stevens et al. 1975). In the Black Hills, by thinning to maintain stand density well below 150 square feet per acre (i.e., 80 square feet per acre), bark beetle outbreaks have apparently been reduced or avoided. Even though actual proof of the effectiveness of thinning is lacking, from the Black Hills evidence it was theorized that thinning of Front Range ponderosa pine stands would result in healthier, faster growing trees less susceptible to mountain pine beetle attack. Subsequent thinnings would be necessary to maintain the stands at a density below 150 square feet per acre.

Because slash may contribute to a stand's susceptibility to attack by providing additional host wood, as well as presenting a greater fire hazard, treatment included chipping, piling and burning, or complete removal of the slash.

\section{Infested Tree Removal}

Trees in the Pilot Project infested with mountain pine beetle were felled and the beetles were destroyed by piling and burning, peeling the bark, chipping, or chemically treating infested trees after they had been felled. Generally, infested tree removal involved felling, bucking into 4-foot lengths and piling the logs into stacks varying in size from one-half cord to several cords. Some infested trees were sold for processing into commercial products. These removals were not included in this study.

\section{Chemical Treatment}

Lindane or ethylene dibromide (EDB) ${ }^{3}$ was applied to the infested stacks of wood in an operation separate from TSI efforts. Chemicals were applied either using jerry cans which were filled with the chemical and carried to the stacks, or by a hose which was attached to a pumper truck filled with the chemical. A plastic

\footnotetext{
${ }^{3}$ The use of trade and company names is for the benefit of the reader; such use does not constitute an official endorsement or approval of any service or product by the U.S. Department of Agriculture to the exclusion of others that may be suitable.
} 
cover was placed over the stacks and secured by filling in trenches which were dug during the TSI operation or just before the chemical was applied.

\section{METHODOLOGY AND RESULTS}

Equations developed in regression analysis are useful for estimation. In this study, the dependent (predicted) variable is the number of hours of labor or machine time, and the independent variables include timber data, terrain, and other characteristics.

\section{Data Collection}

To develop regression equations, it was necessary to consider many variables that might influence costs. Previous attempts to identify cost determinants of standard silvicultural activities (Wikstrom and Alley 1967), as well as direct observation of the various treatment activities in the Pilot Project, provided general guidelines for determining the kind of data needed.

Data for this study were taken primarily from the records of the Colorado State Forest Service (CSFS). Foresters at the Boulder Ranger District of the Arapaho-Roosevelt National Forest, Boulder City and County foresters, and private landowners and landowner associations also were consulted.

\section{TSI - Winter 1977-78}

The first phase of the Pilot Project focused on TSI efforts in four CSFS field units, with data collection concentrated on the one for which TSI cost data were most complete. Twenty-five private ownerships with relatively complete data sets were chosen for analysis. Additional inventory information was taken on elements likely to influence cost, including total acreage treated, acreage thinned, number of beetle-infested trees cut, basal area before treatment, average diameter before treatment, basal area after thinning, average diameter after thinning, percent slope, percent rockiness, and percent of slash disposal completed.

The inventory system used was of a line-plot design, with 0.2 -acre plots for a $10 \%$ sample. The sample points fell at systematic intervals designated beforehand on township maps. The system was designed to be used by one person, with line directions established by a hand compass and intervals between sample points paced. This data and the cost and inventory data provided by CSFS were the essential bases for the analysis. Two separate equations were developed-one predicting hours of labor and one predicting equipment use hours from the cost determinants involved. Hours of labor and machine time were used instead of dollar costs so that the equations could be applied even though labor and machine dollar costs changed considerably.
TSI-Autumn, 1978

Because costs for the first year of the Pilot Project probably would not be representative of costs during subsequent years, additional data were gathered during the second season of TSI activities. Inventory information deemed important, but not available, during the first year was obtained the second year.

Data available from TSI operations in the autumn of 1978 were limited because of bad weather and the increasing use of contract crews to do much of the work (cost breakdown in terms of labor hours and equipment hours was not available from contract crews). However, two CSFS units, Flagstaff and Sugarloaf, provided useful information on state crew activities during this period. An inventory was completed on the site by the unit forester, who compiled the various site characteristics requested. The following information was collected: total acreage treated, basal area before thinning (before BA), average diameter breast height after thinning (d.b.h. after), number of trees thinned per acre, number of beetle-infested trees cut, percent slope, percent rockiness, and special operational difficulties.

\section{Chemical Treatment}

An intensive program to chemically treat the stacks of infested wood that were piled during the first phase of the Project was begun in late spring of 1978. This required spraying the stacks with EDB or lindane and covering them with plastic for approximately 2 weeks. Either of two treatment methods was used, depending on the accessibility of the stacks. One method involved using a hose from a truck to drench the stacks, which were piled as close to roads as possible. The other method, for stacks that were less accessible, was for the slash crews to carry jerry cans, filled with insecticide, to the site, for application. There was greater variability in data for this method because the number of crew members involved and the amount of time spent doing this was not always recorded.

The data for chemical application were collected entirely from one unit, Sugarloaf. These data included listings of landowners whose stacks had been treated on a particular day, the number of cords and stacks treated (size of stacks varied from one-half to approximately two cords) and the names of the participating crew members. With the help of the crew boss at the site, additional data, deemed to be important for predicting costs, were developed, including the relative efficiency for each crew member, the average slope of the tracts treated on one day, and the predominant treatment method used (jerry cans or hose).

Observations for 25 treatment days were selected for the regression because their data sets were most complete, and because the characteristics of the tracts observed throughout a given day were most uniform. 
For example, those days spent treating stacks located on both $0 \%$ and $40 \%$ slopes were not incorporated into the sample. (Daily slope uniformity was necessary because treatment data were only available on a daily basis). The selected data included 9 sets of data for jerry can treatment, 11 sets for hose and truck, and the rest approximately half jerry can and half truck. An attempt was made to rate, using subjective number values, the two treatment types according to their relative degree of difficulty. However, this proved unresponsive in the regression, so it became necessary to devise a separate regression for each operation type, limiting the number of observations for each regression.

Final variables chosen for regression analysis related terrain characteristics and factors of the job done to the number of cords of stacked wood treated per day and included the number of cords treated, size of stacks treated (expressed as percentage of a cord), and the size and the efficiency rating of the crew (on a scale of 1 to 10). For this rating, each crew member was judged separately and the results were compiled to give the crew a daily rating. The most obvious limitation of this rating is that individual crew members produce at varying levels of efficiency, depending on the size of the crew and other crew members with whom they are working.

\section{TSI Prediction Equations}

The original intent was to combine data sets for years 1 and 2 to produce just two regression equations-one for labor hours and one for equipment hours. However, this resulted in regression equations which systematically overestimated the time requirements for year 2, especially for moderately sized jobs. Because treatment productivity increased in the second year, it was more appropriate to develop separate regression equations for each year. Therefore, this section focuses on the development of four prediction equations which include: (1) hours of labor and equipment time as a function of site and stand characteristics on data collected during the first year of TSI activity, and (2) hours of labor and equipment time as a function of site and stand characteristics based on data collected for the second season of TSI field work. Hours of labor and equipment time include only hours actually spent on the site and exclude transportation time. Appendix 1 describes the variables included and the manner in which they were collected.

Several variables were considered (including percent basal area and percent change in average diameter at breast height caused by thinning, as well as number of acres squared) to determine whether a curvilinear model might provide a better fit for the data. Tables 1 and 2 show the important parameters of the data entered in the final runs.

The final TSI regression equations resulting from the analysis based on first year data include:
1. Hours of labor $=-364.87+14.01$ (acres treated) +1.44 (basal area before) $+1,092.52$ (percent rockiness) $+1,178.71$ (percent slope) +2.08 (basal area after).

$\mathrm{R}^{2}=0.93$; standard error of estimate $=103.05$

2. Equipment time (hours) $=173.12+12.38$ (acres thinned) +1.89 (basal area before) +0.66 (number of infested trees cut) +262.43 (percent rockiness).

$\mathrm{R}^{2}=0.88 ;$ standard error of estimate $=67.66$.

The equations based on the second year data were:

1. Hours of labor $=243.32+45.97$ (acres treated) + 2.15 (basal area before) - 68.85 (d.b.h. before) - 0.803 (trees thinned per acre). $\mathrm{R}^{2}=0.90$; standard error of estimate $=108.24$.

2. Equipment time (hours) $=111.31+19.16$ (acres treated) +0.64 (basal area before) -0.28 (trees thinned per acre) -25.64 (d.b.h. before) +0.17 (infested trees cut).

$\mathrm{R}^{2}=0.88$; standard error of estimate $=\mathbf{5 7 . 4 2}$.

Treatment times for people and machines could not be compared directly between year 1 and year 2 because of differences in treatment conditions. Generally, areas treated in year 1 had lower basal area per acre, fewer infested trees cut per acre, and fewer rock obstacles than in year 2 (tables 1 and 2). Labor and equipment hours per acre were inversely proportional to tract size during the first year of the Pilot Project. This pattern can be explained, in part, by

Table 1.- Variables included in regression equations for hours of labor and equipment hours for timber stand improvement, year 1

\begin{tabular}{lrr}
\hline \multicolumn{1}{c}{ Variable } & Mean & Range \\
\hline Total hours of labor & 451.29 & $25-1084$ \\
Acres treated & 16.42 & $2.3-41$ \\
Acres thinned & 11.77 & $0-31$ \\
Infested trees cut & 61.86 & $23-115$ \\
Slope & 0.18 & $0.05-0.35$ \\
Rockiness & 0.15 & $0.10-0.40$ \\
Basal area before & 81.88 & $41-212$ \\
Basal area after & 46.76 & $3-108$ \\
Equipment hours & 207.62 & $10-556$ \\
D.b.h. before & 10.30 & $7.7-12.6$ \\
\end{tabular}

Table 2.-Variables included in the regression equations for hours of labor and equipment hours, year 2

\begin{tabular}{lrr}
\hline \multicolumn{1}{c}{ Variable } & Mean & Range \\
\hline Hours of labor & 249.71 & $6-1148$ \\
Acres treated & 7.33 & $1.5-25$ \\
D.b.h. before & 6.69 & $4-8.5$ \\
Basal area before & 118.57 & $40-190$ \\
Trees thinned/acre & 155.76 & $30-350$ \\
Slope & 0.17 & $0-0.30$ \\
Infested trees cut & 82.24 & $0-615$ \\
Equipment hours & 127.21 & $4-498$ \\
\end{tabular}


the presence of excess workers and equipment on smaller acreages. The extent of the work to be done was often overestimated (particularly in areas of high basal area, slope, etc.) resulting in crews and equipment frequently remaining idle. It is likely that jobs on larger acreages made more efficient use of people and machines. This condition does not appear during the second operating year, where hours per acre are greatest when tract size is large. This may be caused by the longer walking distances required to get to the work area. In general, hours per acre during the second year do not have as wide a range as those for the first year (i.e., changes in plot size and conditions of the terrain do not have as substantial an effect on labor and equipment hours per acre).

Year 1, on the average, required more hours than year 2 to complete similar work, which is typical for the start-up year of a program. Forest managers need time to learn to assess adequately the needs of an area and how best to balance labor and equipment time. Inexperienced crews are more affected by terrain characteristics, such as slope and rockiness, than experienced crews. This is indicated in the regressions for year 1 where, in addition to basal area and the size of the treated tract, slope and rockiness were important productivity determinants.

In effect, year 2 shows that hours to treat are being controlled better than during year 1 . Slope and rockiness no longer have the effect they did during the first year, and are replaced increasingly by characteristics of the job to be done, such as number of trees to be cut per acre in the thinning operation, and number of infested trees cut and stacked. This may be the result of crews becoming more experienced over time.

There are some important cost determinants of the Pilot Project that were not assessed through the regression analysis. Crew experience, and the wide range of ouput levels from one crew member to the next, affect costs considerably particularly in the Pilot Project, where crew members were hired hurriedly and the emphasis at the start was on numbers of workers, rather than quality of their output. This led to a large turnover of crew members during the first year; however, improved hiring and screening procedures resulted in solid, reliable crews by the second operating year. Results showed that crew turnover, and the inefficiency of particular crew members, greatly affects the variability in the total labor and equipment time required to complete a job. In addition to crew variability, unrecorded delays, such as vehicle breakdowns or malfunctioning equipment, affect the time required to complete a job. Until such factors are assessed more accurately, substantial variability will remain unaccounted for in regression analyses.

\section{Chemical Treatment Equations}

The chemical treatment regression analysis was completed by separating the data into two groups: (1) treatment by crews using jerry cans, and (2) treatment using a truck and hose. Appendix 2 defines the variables included. As a result of subdividing the chemical data treatment into these two classes, neither regression had the support of many observations, and the jerry can chemical treatment regression proved to be insignificant. Therefore, this section reports only on the regression developed for the hose and truck treatment, and refers to the jerry can treatment only for general comparison of the two methods.

The regression of truck and hose produced the following prediction equation:

Number of cords treatable per day using truck and hose $=52.40+9.43$ (size of stacks) +2.32 (size of crew) -6.14 (crew efficiency).

$\mathrm{R}^{2}=0.82$ standard deviation of the regression line $=3.35$.

This equation can be used in the field to calculate how many cords could be treated in an 8-hour day, given particular circumstances of stack size, number of crew members, etc. As an example, 18.78 cords could be treated in an 8-hour day when the stacks were onehalf cord in size, and 2 crew members with an efficiency rating of 7 were used. At $\$ 3.50$ per hour for each crew member, the labor cost for treating would be $\$ 56.00$ per day or $\$ 2.93$ per cord. Not included in this estimate are the costs per cord of the chemical and plastic. It is assumed here that stacks to be treated by truck and hose are readily accessible by truck.

It is difficult to explain the negative coefficient of crew efficiency. It is not reasonable that more highly rated crew members would require a longer time to do work of equal quality. Since there was no measure of work quality, it is possible that the more highly rated crews were doing a more thorough job and, therefore, taking more time.

It seems extremely important that anyone working with the chemical be assigned to it willingly. Willingness to work is quite variable, and it was very difficult in the chemical treatment process to control the level of output without direct and constant supervision of the employees. The size of the crew is somewhat important. The most efficient crew size for this job is two workers, because drenching stacks and covering them with plastic is basically a two-person job. Because a knowledgeable person is likely to handle the chemical more responsibly, better performance was obtained during the second year when treatment was begun in May after forestry undergraduate students were available for summer work.

Terrain features, such as slope, clearly influence the amount of time required to carry cans to a site. Other obstacles include down trees, deep snow, and thick slash left from TSI activities. Piling stacks of wood as close to accessible roads as possible helps eliminate time-consuming walks during the chemical operation. It is important to stack the wood away from rocky soils and other impediments to reduce the amount of time spent digging trenchs around the stacks. Observations by crew bosses on the sites indicate that it may be more efficient for slash crews to dig the trenches after 
making the stacks rather than have chemical crews both dig and treat. Possibilities for improving efficiency in these activities warrant further attention and analysis.

The number of stacks treated per day using truck and hose was highly correlated to the size of the stacks because driving time will be much greater if the stacks are small and spread over large areas. Optimal stack size has been estimated to be approximately 4 cords, because larger sizes require an unwieldy amount of plastic. Chemical treatment work is subject to potential unplanned costs similar to those that affect TSI operations, such as equipment breakdowns and associated maintenance time. But since these events were generally not recorded or quantified for either treatment, it is difficult to evaluate their impact.

\section{Range and Limitations}

The regression equations in this study should be used only over the range of data collected in the sample, with the additional caution that predictions are more accurate in the middle range of each independent variable. Use of the equations outside of these ranges results in the possibility of very large errors. As the values of the independent variables deviate from the means, the regression confidence interval becomes larger. The relevant ranges for the variables for each of the equations are shown by tables $1,2,3$, and 4 .

Table 3.-Variables in the regression equation to predict chemical treatment capability per day by truck

\begin{tabular}{lrr}
\hline \multicolumn{1}{c}{ Variable } & Mean & Range \\
\hline Cords treated per day & 20.06 & $13.5-31.25$ \\
Size of stack & 1.03 & $0.56-1.64$ \\
Crew size & 2.54 & $1-4$ \\
Slope & 0.24 & $0.20-0.40$ \\
Crew efficiency & 7.82 & $7-8.5$ \\
\end{tabular}

Table 4.- Variables in the regression equation to predict chemical treatment capability per day by jerry cans

\begin{tabular}{lrr}
\hline \multicolumn{1}{c}{ Variable } & Mean & Range \\
\hline Cords treated per day & 25.26 & $12-53.5$ \\
Size of stack & 1.07 & $0.81-1.40$ \\
Crew size & 3.0 & $2-4$ \\
Slope & 0.34 & $0.20-0.40$ \\
Crew efficiency & 7.70 & $6.6-8.5$
\end{tabular}

\section{ADDITIONAL FACTORS}

\section{Labor}

Contract defaults were a problem in the Pilot Project. The additional cost and effort required to cope with them pointed up the need to analyze bids and bid- ders carefully. The regression equations presented can be used to predict the total hours required to treat a particular tract and, thus, enable the forest manager to determine more accurately whether a bid from a contractor is realistic.

\section{Planning and Coordination}

It is important that management plans be based on fact-actual conditions and needs of a forest, not tentative evaluations-to avoid changes in expectations and/or costs. The degree to which management prescriptions and other plans can be formulated depends upon the likelihood and level of future funding for a designated area. Although waiting for funding before beginning the planning stage can cause the loss of valuable field time once money is available, it is often considered too risky to allocate money to planning before funds are assured.

Also considered important to the success of vegetation management programs is coordinating tasks to avoid unnecessary duplication or overlap. For instance, in the Pilot Project some unit foresters complained that excess time was spent in locating areas that could have been better identified and mapped on early visits to that site by inventory or marking crews. Further, the more completely slash is disposed of during the TSI operation, the easier and less timeconsuming it is for chemical treatment crews to move around in the woods treating infested stacks. If all tasks requiring similar effort and equipment are completed during one phase of the operation, costs can usually be reduced.

\section{Generating Revenues}

As noted earlier, revenues generated from sale of removed timber can be used to help offset treatment costs. Future vegetation management programs along the Front Range may need to rely more heavily upon the generation of revenues. The CSFS considered the revenue-generating phase of the Pilot Project to be successful. Despite the fact that stumpage purchasers got a late start in harvesting, the winter of 1977-78 was especially mild and did not hinder harvesting. Markets for lumber products were especially strong along the Front Range during this period.

It would be of great benefit to future mountain pine beetle control projects if salable products could be developed from the huge volumes of residues now left on the forest floor after a conventional harvest. Much of this wood is now wasted, and even worse, it contributes to the fire hazard. Because it has not been economical to remove most of this material, it has been burned in place. Possible new products from this waste include alcohol, charcoal, or chips pressed into pellets for fuel use. If harvesting and processing of slash material into products were properly timed, most of the chemical treatment of slash could be eliminated. Since the com- 
pletion of this Pilot Project and particularly during the autumn of 1979, the demand for and prices of firewood have increased tremendously in the Front Range area (Hostetler 1980). This increased demand for firewood makes vegetation management more appealing and more feasible. Sale of firewood can provide a means for removing some of the material that needs to be taken out and also provides the owner with funds to finance other activity, such as chemical treatment.

\section{LITERATURE CITED}

Hostetler, Ken. 1980. Denver area firewood survey. Colorado Forest Products Marketing Bulletin 14(1):5. Colorado State Forest Service. Fort Collins, Colo.
Stevens, Robert E., Clifford A. Meyers, William F. McCambridge, George L. Downing, and John G. Lant. 1975. (revised) Mountain pine beetle in Front Range ponderosa pine: What it's doing and how to control it. USDA Forest Service General Technical Report RM-7, 3 p. Rocky Mountain Forest and Range Experiment Station, Fort Collins, Colo.

Wikstrom J. H., and J. R. Alley. 1967. Cost control in timber growing on the National Forests of the Northern Region. USDA Forest Service Research Paper INT-42, 37 p. Intermountain Forest and Range Experiment Station, Ogden, Utah.

\section{Pesticide Precautionary Statement}

Pesticides used improperly can be injurious to man, animals, and plants. Follow the directions and heed all precautions on the labels.

Store pesticides in original containers under lock and key-out of the reach of children and animals - and away from food and feed.

Apply pesticides so that they do not endanger humans, livestock, crops, beneficial insects, fish, and wildlife. Do not apply pesticides when there is danger of drift, when honey bees or other pollinating insects are visiting plants, or in ways that may contaminate water or leave illegal residues.

Avoid prolonged inhalation of pesticide sprays or dusts; wear protective clothing and equipment if specified on the container.

If your hands become contaminated with a pesticide, do not eat or drink until you have washed. In case a pesticide is swallowed or gets in the eyes, follow the first-aid treatment given on the label, and get prompt medical attention. If a pesticide is spilled on your skin or clothing, remove clothing immediately and wash skin thoroughly.

Do not clean spray equipment or dump excess spray material near ponds, streams, or wells. Because it is difficult to remove all traces of herbicides from equipment, do not use the same equipment for insecticides or fungicides that you use for herbicides.

Dispose of empty pesticide containers promptly. Have them buried at a sanitary land-fill dump, or crush and bury them in a level, isolated place.

NOTE: Some states have restrictions on the use of certain pesticides. Check your state and local regulations. Also, because registrations of pesticides are under constant review by the Federal Environmental Protection Agency, consult your county agricultural agent or state extension specialist to be sure the intended use is still registered.

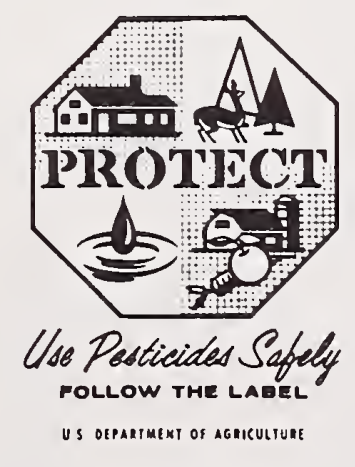




\section{APPENDIX 1.-DEFINITION OF TSI VARIABLES}

Total hours of labor.-Hours spent by crews thinning, cutting, and stacking infested trees, and disposing of slash, through burning, lopping and scattering, or chipping.

Total equipment time.-Total operating hours for equipment on the site, such as chainsaws or chipper.

Acres treated.-Total acreage on which green trees were thinned and infested trees cul, stacked, and chemically treated.

Acres thinned.-Total acreage on which stands thinned to prescribed basal area. No infested trees cut.

Slope.-Percentage slope (expressed as decimal) measured by a clinometer or Abney level.

Rockiness.-Subjective evaluation of percentage of ground covered by rocky outcroppings or boulders.

Basal area before treatment.-Basal area of stand before treatment in square feet per acre as determined with an angle gage device.

Basal area after treatment.-Basal area of stand after treatment.

D.B.H. before treatment.-Average diameter breast height in inches before treatment.
Trees thinned/acre.-Number of uninfested trees thinned on each acre.

Infested trees cut.-Number of infested trees cut and stacked per tract.

\section{APPENDIX 2.-DEFINITION OF CHEMICAL TREATMENT VARIABLES.}

Cords treated/day.-Number of cords treated in an 8-hour day using different treatment methods.

Size of stack.-Average size of stacks treated in an 8-hour day, expressed as a percentage of a cord.

Crew size.-Number of workers on a crew; slash crew workers who placed cans at the site for chemical crews were counted as half-time workers.

Slope.-Average slope of tracts treated in a 1-day period, estimated by crew boss on the site.

Crew efficiency.-Each crew member was given a subjective rating by the crew boss on a scale of 1-10, 1 being the lowest. Based on these ratings, the crew was assigned a weighted rating. 


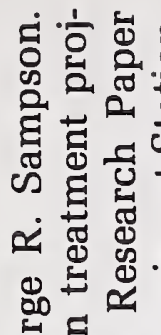

额。

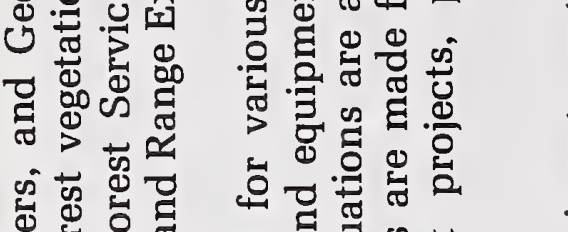

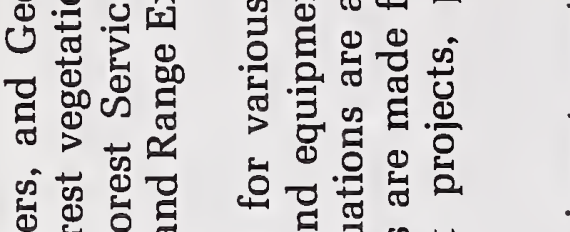

密

客我



낭

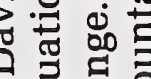

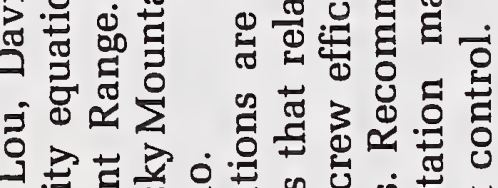

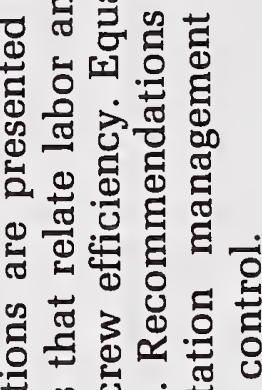

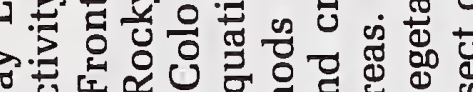

空

-

曾

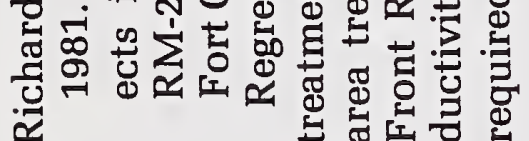

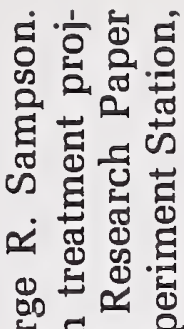

今. 8 .

0 단.

要然此

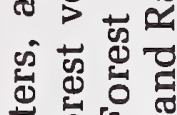

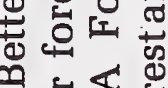

mis

든.

羟

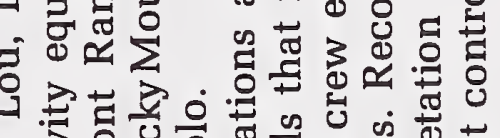

>

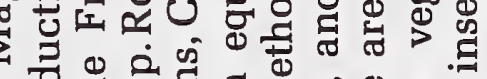

둥ㅎㅇ

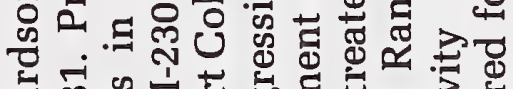

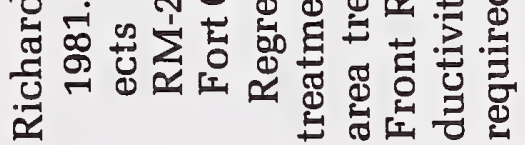

ปี

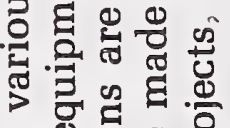

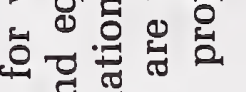

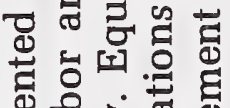

过

a.

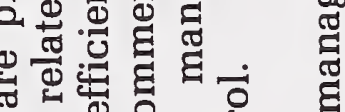

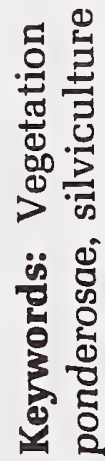

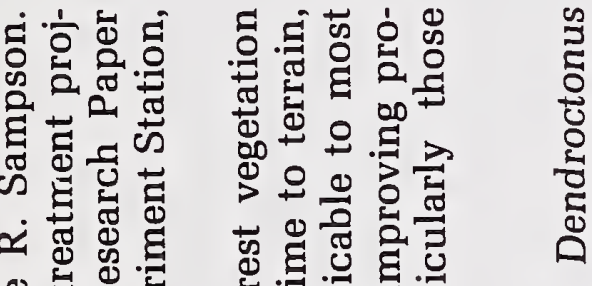



कั. 워

i क

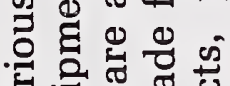

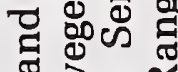

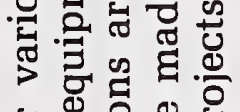

क幽元

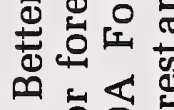

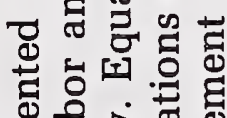

政

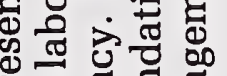

氜

응

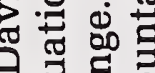

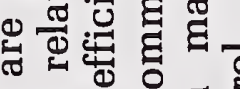

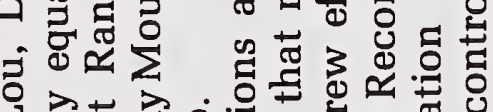

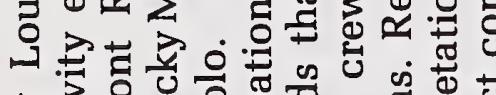

ब.

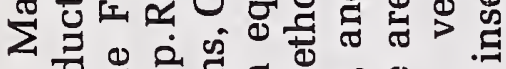

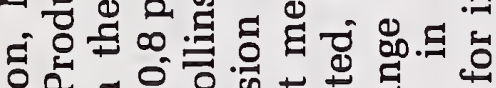

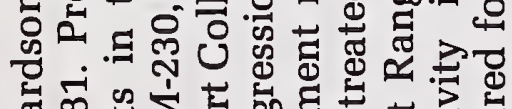

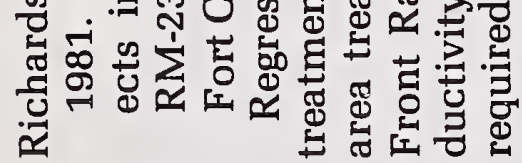

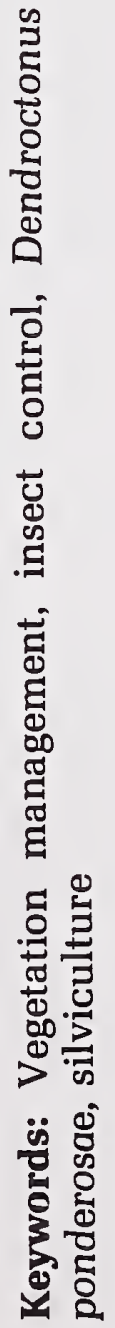

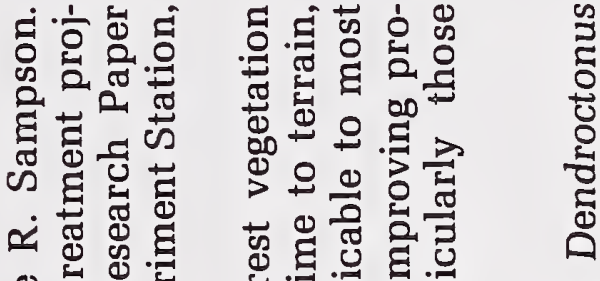

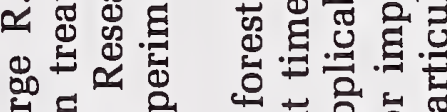

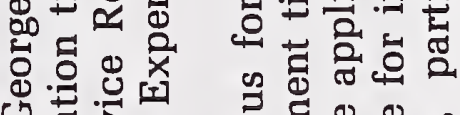

o

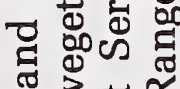

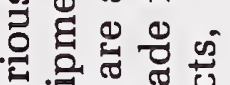

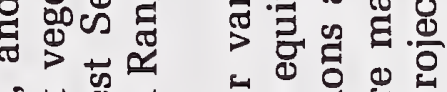

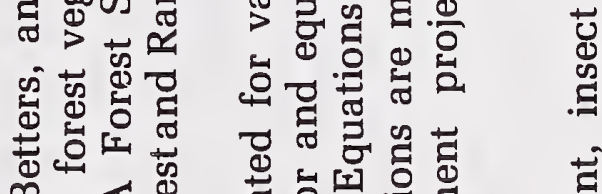

象若

뭉ㄱำ

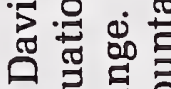

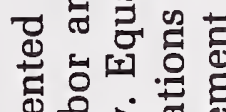

远究

过.

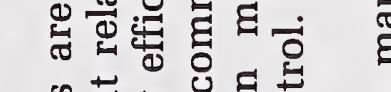

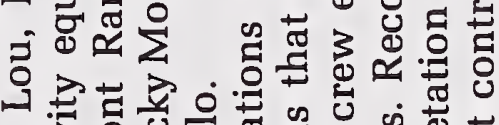

官

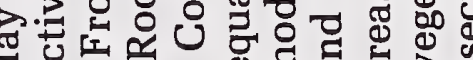

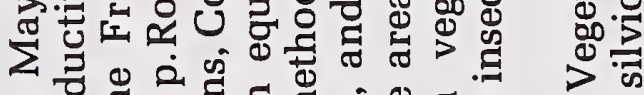

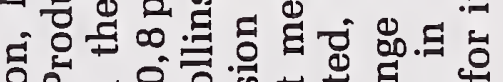

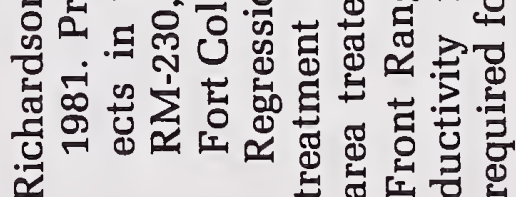






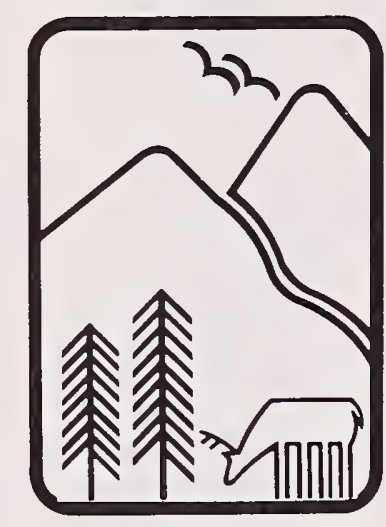

Rocky
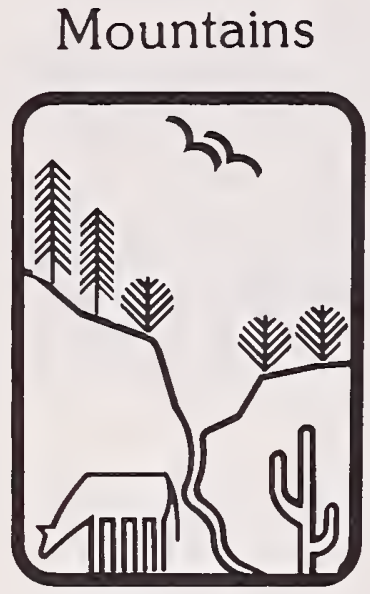

Southwest

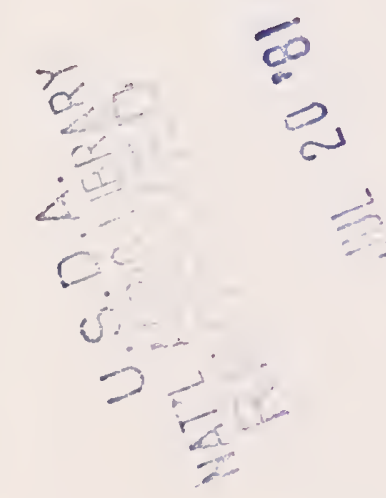<smiles>[CH]1[CH]C1</smiles>

U.S. Department of Agriculture Forest Service

Rocky Mountain Forest and Range Experiment Station

The Rocky Mountain Station is one of eight regional experiment stations, plus the Forest Products Laboratory and the Washington Office Staff, that make up the Forest Service research organization.

\section{RESEARCH FOCUS}

Research programs at the Rocky Mountain

Station are coordinated with area universities and with other institutions. Many studies are conducted on a cooperative basis to accelerate solutions to problems involving range, water, wildlife and fish habitat, human and community development, timber, recreation, protection, and multiresource evaluation.

\section{RESEARCH LOCATIONS}

Research Work Units of the Rocky Mountain Station are operated in cooperation with universities in the following cities:

Albuquerque, New Mexico

Bottineau, North Dakota

Flagstaff, Arizona

Fort Collins, Colorado*

Laramie, Wyoming

Lincoln, Nebraska

Lubbock, Texas

Rapid City, South Dakota
Tempe, Arizona
Great
Plains

Station Headquarters: 240 W. Prospect St., Fort Collins, CO 80526 